\title{
Plasma and cerebrospinal fluid interleukin- $1 \beta$ during lipopolysaccharide-induced systemic inflammation in ewes implanted or not with slow-release melatonin
}

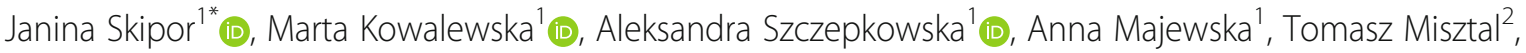 \\ Marek Jalynski ${ }^{3}$, Andrzej P. Herman ${ }^{2}$ and Katarzyna Zabek ${ }^{4}$
}

\begin{abstract}
Background: Interleukin-1 $\beta$ (IL-1 $\beta$ ) is important mediator of inflammatory-induced suppression of reproductive axis at the hypothalamic level. At the beginning of inflammation, the main source of cytokines in the cerebrospinal fluid (CSF) is peripheral circulation, while over time, cytokines produced in the brain are more important. Melatonin has been shown to decrease pro-inflammatory cytokines concentration in the brain. In ewes, melatonin is used to advance the onset of a breading season. Little is known about CSF concentration of IL-1 $\beta$ in ewes and its correlation with plasma during inflammation as well as melatonin action on the concentration of IL-1 $\beta$ in blood plasma and the CSF, and brain barriers permeability in early stage of lipopolysaccharide (LPS)-induced inflammation.

Methods: Systemic inflammation was induced through LPS administration in melatonin- and sham-implanted ewes. Blood and CSF samples were collected before and after LPS administration and IL-1 $\beta$ and albumin concentration were measured. To assess the functions of brain barriers albumin quotient (QAlb) was used. Expression of IL-1 (I/1B) and its receptor type I (I/1r1) and type II (I/1r2) and matrix metalloproteinase (Mmp) 3 and 9 was evaluated in the choroid plexus (CP).

Results: Before LPS administration, IL-1 $\beta$ was on the level of $62.0 \pm 29.7 \mathrm{pg} / \mathrm{mL}$ and $66.4 \pm 32.1 \mathrm{pg} / \mathrm{mL}$ in plasma and $26.2 \pm 5.4 \mathrm{pg} / \mathrm{mL}$ and $21.3 \pm 8.7 \mathrm{pg} / \mathrm{mL}$ in the CSF in sham- and melatonin-implanted group, respectively. Following LPS it increased to $159.3 \pm 53.1 \mathrm{pg} / \mathrm{mL}$ and $197.8 \pm 42.8 \mathrm{pg} / \mathrm{mL}$ in plasma and $129.8 \pm 54.2 \mathrm{pg} / \mathrm{mL}$ and $139.6 \pm 51.5 \mathrm{pg} / \mathrm{mL}$ in the CSF. No correlations was found between plasma and CSF IL-1 $\beta$ concentration after LPS in both groups. The QAlb calculated before LPS and $6 \mathrm{~h}$ after was similar in all groups. Melatonin did not affected mRNA expression of $/ 11 B, \| 1 r 1$ and $/ 11 \mathrm{r} 2$ in the CP. The mRNA expression of Mmp3 and Mmp9 was not detected.

Conclusions: The lack of correlation between plasma and CSF IL-1 $\beta$ concentration indicates that at the beginning of inflammation the local synthesis of $\mathrm{IL}-1 \beta$ in the $C P$ is an important source of IL-1 $\beta$ in the CSF. Melatonin from slow-release implants does not affect IL-1 $\beta$ concentration in plasma and CSF in early stage of systemic inflammation.
\end{abstract}

Keywords: Albumin, Cerebrospinal fluid, Ewes, Interleukin -1ß, LPS, Melatonin

\footnotetext{
* Correspondence: j.skipor@pan.olsztyn.pl

${ }^{1}$ Institute of Animal Reproduction and Food Research, Polish Academy of

Sciences, Olsztyn, Poland

Full list of author information is available at the end of the article
} 


\section{Background}

It is well established that immune stress caused by infections and inflammatory diseases reduces animals productivity and is a powerful modulator of mechanisms regulating reproduction at all levels of the hypothalamic-pituitary-gonadal axis [1]. A few pathways have been suggested to be responsible for the immunemediated inhibition of reproductive activity at the level of hypothalamus and one of these involves proinflammatory mediators such as cytokines [2]. Hypothalamic interleukin (IL)-1 $\beta$ and tumor necrosis factor (TNF)- $\alpha$ mediates the lipopolysaccharide (LPS)-induced suppression of gonadotropin releasing hormone (GnRH) and luteinizing hormone (LH) release in female rats [3]. In ewes, the central IL-1 $\beta$ is an important modulator of the $\mathrm{GnRH}$ biosynthesis and release during immune/inflammatory challenge. The thesis about the crucial role of these cytokines in the transmission of signals from the immune to neuroendocrine systems seems to be supported by the presence of IL- $1 \beta$ and its receptors in the hypothalamus in LPS-treated ewes [4].

In general, passage of molecules from the periphery to the brain is restricted by brain barriers: blood-brain barrier (BBB) located in cerebromicrovascular endothelial cells and blood-cerebrospinal fluid barrier (BCSFB) located in the epithelial cells of choroid plexus (CP) [5]. The origin of central pro-inflammatory cytokines is differentiated. At the beginning of inflammation, the main source of cytokines present in the cerebrospinal fluid (CSF) is peripheral circulation, while over time of inflammation, endogenous cytokines produced in the brain seems to be more important. In rats treated intravenously with IL-1 $\beta$ two waves of cellular activation at the brain appears, the first one at the blood side of the BBB 30 min after IL-1 $\beta$ administration and then after $3 \mathrm{~h}$ at the parenchymal side of the BBB [6]. It has been demonstrated in rats, that early after ( $5 \mathrm{~h}$ ) injection of IL-1 $\beta$ to the brain BBB becomes permeable to intravenously administered contrast [7]. In this process matrix metalloproteinases (MMPs) as enzymes that catalyze the proteolytic cleavage of basal lamina components and thus remodeling of the extracellular matrix and brain barriers permeability play an important role [8]. Interestingly, melatonin attenuated BBB hyperpermeability in IL-1 $\beta$ stimulated rat brain microvessels endothelial cells in vitro as well as in vivo in mouse traumatic brain injury model [9]. From the periphery, IL-1 $\beta$ is transported throughout the brain barriers [10]. Transport of IL-1 $\beta$ has been suggested to occur via a type II IL-1 receptor [11]. This receptor may also be released from cells and function as decoy receptor to block IL-1 $\beta$ action in contrast to type I IL- $1 \beta$ receptor that transduce IL- 1 signals after binding with IL-1 $\beta[12,13]$. Expression of type II IL-1 receptor mRNA (Il1r2) and I IL-1 $\beta$ receptor (Il1r1) was detected in the brain endothelial cells [14] and in the CP [15]. In ewes, intravenous injection of LPS is one model of systemic inflammation which has been used to study mechanisms responsible for the immune-mediated inhibition of reproductive activity [4]. So far little is known about CSF concentration of IL-1 $\beta$ in ewes and its correlation with plasma concentration during LPSinduced systemic inflammation. Melatonin receptors MT1 and MT2 has been demonstrated in the ovine CP what unable direct melatonin action on the CP [16]. Melatonin action on the concentration of IL- $1 \beta$ in blood plasma and the CSF is particularly interesting due to the use of melatonin from continuous slow-release implants to advance the onset of a breeding season in sheep and goats [17].

The present study aimed at evaluating effect of LPS alone and with melatonin slow-release implants on the concentration of IL-1 $\beta$ in blood plasma and the CSF as well as on the BBB permeability in ewes early after LPS administration. Additionally, we evaluated effect of melatonin implantation on mRNA expression of $I l 1 B$ and its receptors Il1r1 and Il1r2 as well as Mmp3 and $M m p 9$ in the CP under the influence of IL-1 $\beta$.

\section{Methods}

\section{Animals and experimental design}

All animal procedures were conducted in accordance with the Polish Guide for the Care and Use of Animals and approved by the Local Ethics Committee (No. 25/ 2012). Female adult sheep (4-5 years old, 50-60 kg body weight) of the Blackheaded Mutton breed $(n=14)$ were maintained indoors under natural lighting conditions (latitude $52^{\circ} \mathrm{N}, 21^{\circ} \mathrm{E}$ ) and fed a constant diet of hay, straw and commercial concentrates according to the recommendations proposed by the National Research Institute of Animal Production for adult ewes. Water and mineral licks were available ad libitum. On the beginning of May, ewes were ovariectomized under general anaesthesia and then (middle of May) subcutaneously implanted with an oestradiol (E2) implant, which maintained plasma E2 concentrations of 2-4 pg/L [18]. After 2 wk of recovery ewes were implanted under general anaesthesia with stainless steel guide cannulae $(1.2 \mathrm{~mm}$ o.d.) into the third ventricle as described earlier [19]. In the middle of May, ewes were first sampled for blood and then one- half of the animals was randomly melatonin-implanted $(n=7$, slow-release implant of $18 \mathrm{mg}$, Melovine Ceva Sante Animale, France) and the second half of the animals was sham-implanted $(n=7)$. Approximately $40 \mathrm{~d}$ later, ewes were implanted with the jugular vein catheter early on the morning (7:00 am) and have been placed in individual cages where they could lie down and have access to hay and water. To prevent the stress of social isolation, all ewes had visual contact. 
After that stainless catheter was introduced into the third ventricle and control blood and CSF samples were collected. Then immune stress was induced by intravenously injection of LPS from Escherichia coli 055:B5 (Sigma, USA), at the dose of $400 \mathrm{ng} / \mathrm{kg}$ of body weight, dissolved in saline $(0.9 \% w / v \mathrm{NaCl})$ at a concentration of $10 \mathrm{mg} / \mathrm{L}(10 \mu \mathrm{g} / \mathrm{mL})$ as it was used previously in ewes [20]. The individual body mass of experimental ewes were at the range of $52 \mathrm{~kg}$ to $63 \mathrm{~kg}$, therefore injection volume of LPS solution/saline was at the range of 2.1 to $2.5 \mathrm{~mL}$. Body temperature was measured before and after LPS administration. Blood plasma was collected just before and after melatonin implantation and then every hour after LPS administration (Fig. 1). Blood samples were collected through a catheter inserted into the jugular vein. First $2 \mathrm{~mL}$ of blood samples were removed then $10 \mathrm{~mL}$ were collected into the tubes with stabilizer (EDTA). Immediately after centrifuging, the blood plasma were divided into separate $(1 \mathrm{~mL})$ aliquots and stored at $-40{ }^{\circ} \mathrm{C}$ until assayed for IL- $1 \beta$ and albumin. To collect the CSF samples, a stainless steel catheter (1.0 mm o.d., $0.8 \mathrm{~mm}$ i.d.) was carefully introduced into the guide cannula and connected to a special cannulaEppendorf tube system joined to a PHD 2000 infuse/ withdrawal pump (Hugo Sachs Elektronik Harvard Apparatus, Germany). The CSF collection from the third ventricle of conscious ewes was performed during a $7 \mathrm{~h}$ period ( $1 \mathrm{~h}$ before and $6 \mathrm{~h}$ after LPS administration) at a rate of $20 \mu \mathrm{L} / \mathrm{min}$. The tubes of CSF samples were kept in an ice bath during sampling, and the volume of one sample collected during the $30 \mathrm{~min}$ period was about $500 \mu \mathrm{L}$. Immediately after filling, the tubes were stored at $-80{ }^{\circ} \mathrm{C}$ until assayed for IL-1 $\beta$ and albumin. The ewes were euthanized $6 \mathrm{~h}$ after LPS administration. After decapitation, the brains were dissected, CP were removed from their anchoring to the Galien's vein and the split was made along the mid-line, separating the CP from each lateral ventricle. CPs were then immediately frozen in liquid nitrogen and stored at $-80{ }^{\circ} \mathrm{C}$ until use.

\section{Hormones and IL-1 $\beta$ concentration measurement}

The ability of the melatonin implants to maintain permanently high blood concentrations of melatonin was monitored by determining melatonin concentrations in blood plasma samples obtained before and $40 \mathrm{~d}$ after melatonin-implantation using radioimmunoassay (RIA) described by Misztal et al. [21]. The assay sensitivity for melatonin was $16.8 \pm 8.0 \mathrm{pg} / \mathrm{mL}$, and the intra- and interassay coefficients of variations were 10.5 and $13.2 \%$, respectively. Blood plasma and CSF IL- $1 \beta$ concentrations were determined by commercially available enzymelinked immunosorbent assay (ELISA Kit for ovine Interleukin $1 \beta$, Cloud-Clone Corp., USA), following the manufacturer's instructions. The optical density of individual wells was measured by a spectrophotometric microplate reader (Epoch, BioTek, Switzerland) at a wavelength of $450 \pm 10 \mathrm{~nm}$. The concentration of IL- $1 \beta$ in samples were determined by comparing the optical density of the samples to the standard curve. The detection limit of the assay was less than $5.9 \mathrm{pg} / \mathrm{mL}$.

\section{Western blotting and CSF/blood plasma quotient}

To assess the functions of BCSFB albumin quotient (QAlb) was used. The CSF and blood plasma samples (equal volume $16 \mu \mathrm{L}$ CSF and diluted blood plasma (1:160) with addition of $4 \mu \mathrm{L}$ of loading buffer) from the sham- and melatonin-implanted group (one animal from each group) were loaded onto $10 \%$ sodium dodecyl sulfate (SDS) polyacrylamide gels together with serial dilutions of sheep serum albumin (SSA, Biorbyt, USA,

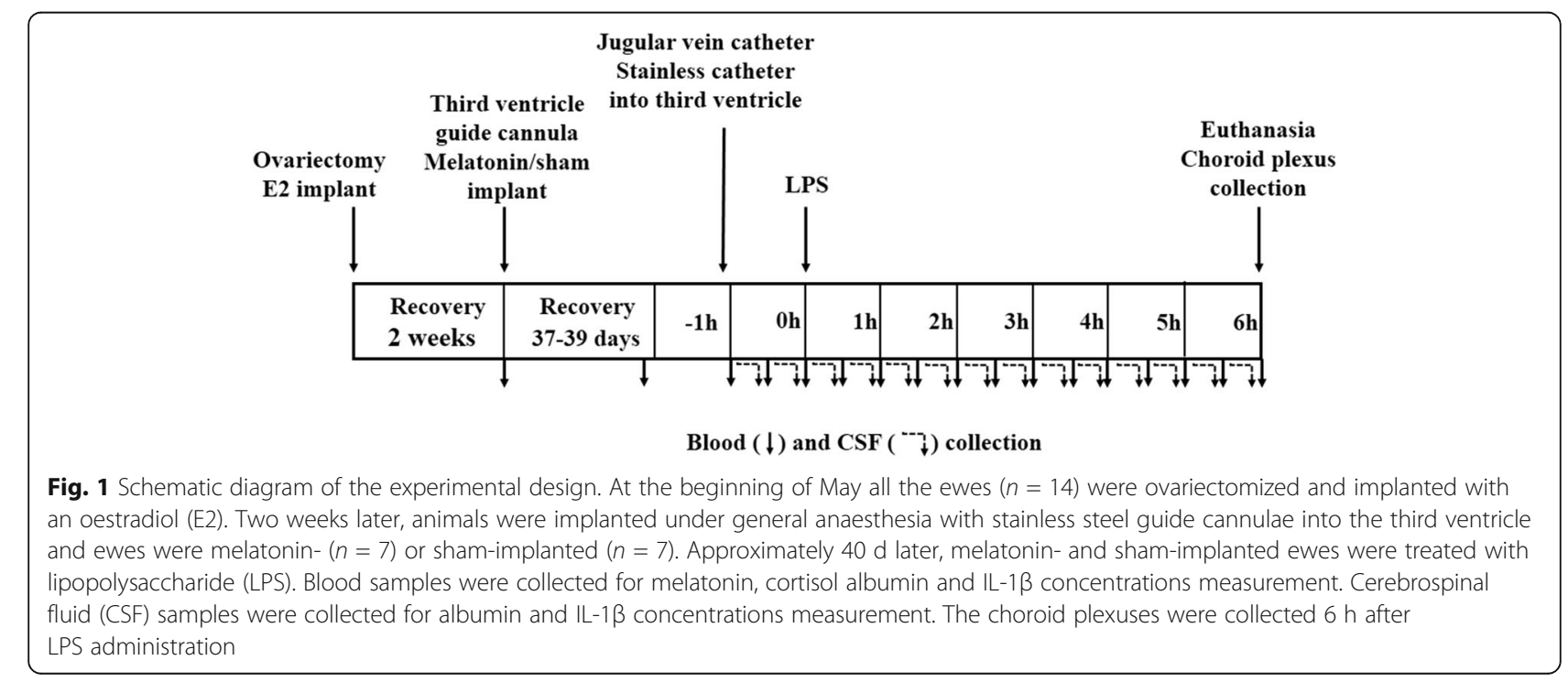


range 0.25 to $5 \mu \mathrm{g} / \mu \mathrm{L})$. Electrophoresis was performed using the MiniProtean II electrophoretic apparatus (BioRad, USA) at $60 \mathrm{mV}$ constant voltage. Thereafter, proteins were transferred onto $0.2 \mu \mathrm{m}$ thick nitrocellulose membranes (Whatman Inc., Germany) at $30 \mathrm{~V}$ for $1.5 \mathrm{~h}$ in a semi-dry transfer system (BioRad, USA). After $1.5 \mathrm{~h}$ blocking with block buffer (TBST, $50 \mathrm{~g} / \mathrm{L}$ nonfat milk in $10 \mathrm{~mL}$ Tris buffer saline containing $0.5 \%$ Tween 20) at room temperature, the membranes were extensively washed in TBST and incubated overnight at $4{ }^{\circ} \mathrm{C}$ with rabbit polyclonal antibodies against sheep albumin at 1:300 dilution (Anitbodies-online, Germany). After final wash, membranes were developed using chemiluminescence SuperSignal ${ }^{\circ}$ West Dura Kit (Thermo Scientific, USA) and visualized by VersaDoc 4000 MP Imaging System (BioRad, USA). Based on a SSA dilution curve, the albumin concentration was calculated in both CSF and blood plasma samples by measuring optical densities of the bands (Image Lab 5.2.1, Software, BioRad, USA). The integrity of BCSFB was estimated by the ratio of albumin concentrations in CSF and blood plasma. The albumin quotient was evaluate as follows: QAlb = Alb (CSF)/ Alb (blood plasma).

\section{Relative gene expression assays}

The total RNA from the CP was isolated using NucleoSpin RNA II Kit (Marcherey-Nagel, Germany). All steps of the isolation were performed according to the manufacturer's protocol. The purity and concentration of the isolated RNA were quantified spectrophotometrically using a NanoDrop 1000 instrument
(Thermo Fisher Scientific, USA). The integrity of RNA was verified by electrophoresis using $1.2 \%$ agarose gel stained with ethidium bromide (Sigma Aldrich, USA). To synthesize cDNA, the DyNAmo cDNA Synthesis Kit (Thermo Fisher Scientific, USA) and $1 \mu \mathrm{g}$ of total RNA were used. Expression of interleukin $1 \beta$ (Il1B) and its receptor type I (Il1r1) and type II (Illr2) and matrix metalloproteinases $(M m p) 3$ and 9 in the ovine CP was determined by real-time PCR. Specific primer pairs for the different genes were used according to the literature or were designed using Primer-BLAST (National Center for Biotechnology Information) and were synthesized by Genomed (Poland) and are presented in Table 1. One reaction mixture for real-time PCR reaction $(10 \mu \mathrm{L})$ contained $3 \mu \mathrm{L}$ of diluted (1:14 reference genes, 1:10 Il1B, Il1r1, Illr2 and 1:8 Mmp3 and Mmp9) cDNA, $0.2 \mu \mathrm{mol} / \mathrm{L}$ of the forward and reverse primers and $5 \mu \mathrm{L}$ of mastermix from a DyNAmo SYBR Green qPCR Kit with ROX (Thermo Fisher Scientific, USA). The following protocol was used: $95{ }^{\circ} \mathrm{C}$ for $10 \mathrm{~min}$ for Hot Start modified Tbr DNA polymerase, followed by 35 cycles of $15 \mathrm{~s}$ of denaturation at $95{ }^{\circ} \mathrm{C}, 30 \mathrm{~s}$ of annealing at $\mathrm{X}{ }^{\circ} \mathrm{C}$ (see Table 1) and $30 \mathrm{~s}$ of extension at $72{ }^{\circ} \mathrm{C}$. After the cycles, a final melting curve analysis under continuous fluorescence measurement was performed to evaluate the specific amplification. The results were analyzed using Real-time PCR Miner (on-line available: http://www.miner.ewindup.info/version2), based on the algorithm developed by Zhao and Fernald [22].

Table 1 Sequences of oligonucleotide primers used for real time-PCR

\begin{tabular}{|c|c|c|c|c|c|c|}
\hline GenBank Acc. No. & Gene & $\begin{array}{l}\text { Amplicon } \\
\text { size, bp }\end{array}$ & $\begin{array}{l}\text { Temp. of primers } \\
\text { annealing, }{ }^{\circ} \mathrm{C}\end{array}$ & $\begin{array}{l}\text { Forward/ } \\
\text { reverse }\end{array}$ & $\begin{array}{l}\text { Sequence } \\
5^{\prime} \rightarrow 3^{\prime}\end{array}$ & Reference \\
\hline \multirow[t]{2}{*}{ X54796.1 } & $\| 1 B$ & 137 & 59 & forward & CAGCCGTGCAGTCAGTAAAA & {$[35]$} \\
\hline & & & & reverse & GAAGCTCATGCAGAACACCA & \\
\hline \multirow[t]{2}{*}{ NM_001206735.1 } & $\| 1 r 1$ & 124 & 59 & forward & GGGAAGGGTCCACCTGTAAC & {$[35]$} \\
\hline & & & & reverse & ACAATGCTTTCCCCAACGTA & \\
\hline \multirow[t]{2}{*}{ NM_001046210 } & $111 r 2$ & 161 & 59 & forward & CGCCAGGCATACTCAGAAA & [36] \\
\hline & & & & reverse & GAGAACGTGGCAGCTTCTTT & \\
\hline \multirow[t]{2}{*}{ XM_004015970.1 } & Mmp3 & 112 & 60 & forward & AAGGCAGACATTITTGGCGG & Originally designed \\
\hline & & & & reverse & ATGCCTCTTGGGGAACCTGC & \\
\hline \multirow[t]{2}{*}{ XM_004014614.1 } & Mmp9 & 115 & 60 & forward & CTTCCGATGGAAAGAACGGGC & Originally designed \\
\hline & & & & reverse & GGGATCACAACGCCTITGC & \\
\hline \multirow[t]{2}{*}{ NM_001034034 } & Gapdh & 143 & 60 & forward & TGACCCCTTCATTGACCTTC & [27] \\
\hline & & & & reverse & GATCTCGCTCCTGGAAGATG & \\
\hline \multirow[t]{2}{*}{ NM_001009784.1 } & Actb & 122 & 60 & forward & GCCAACCGTGAGAAGATGAC & [27] \\
\hline & & & & reverse & TCCATCACGATGCCAGTG & \\
\hline \multirow[t]{2}{*}{ BC_108088.1 } & Hdacl & 115 & 60 & forward & CTGGGGACCTACGGGATATT & [35] \\
\hline & & & & reverse & GACATGACCGGCTTGAAAAT & \\
\hline
\end{tabular}




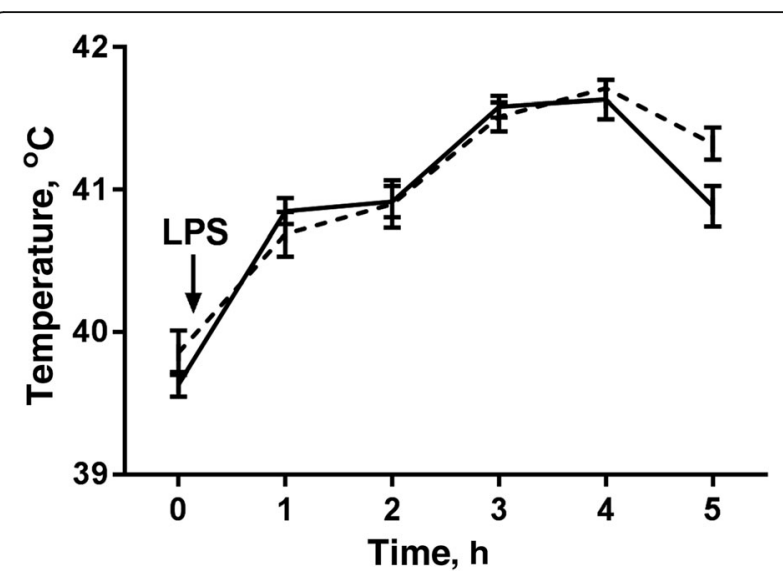

Fig. 2 The mean $( \pm S E M)$ body temperature before and every $1 \mathrm{~h}$ for $5 \mathrm{~h}$ after LPS treatment in sham-implanted (solid line) and melatonin-implanted (dotted line) adult ewes

\section{Statistical analysis}

All data are presented as the mean \pm standard error of the mean $[S E M]$. The real-time PCR results are presented as the relative gene expression of the target gene vs. the mean of 3 reference genes (Gapdh, Actb, Hdac1). The body temperature, melatonin and IL-1 $\beta$ concentrations, were analyzed by a one-way ANOVA for repeated measures and relative gene expression by t-test using PRISM 6 GraphPad Software (San Diego, USA). For statistical analysis, percentage data of QAlb were multiplied by 0.1 and then arcsin transformed according to the eq. $(\mathrm{Y}=$ deg. $(\arcsin (\operatorname{sqrt}(\mathrm{Y} / 100)))$ using PRISM 6 GraphPad Software. The transformed data were subjected to oneway ANOVA. Additionally, the differences between QAlb in sham-and melatonin-implanted ewes before LPS administration were analyzed by Welch test. The relationship between variables was analyzed using Pearson's correlation coefficient. Statistical significance was assumed at $P<0.05$.

\section{Results}

The mean body temperature before the LPS administration was $39.6 \pm 0.1{ }^{\circ} \mathrm{C}$ in the sham-implanted group and $39.9 \pm 0.2{ }^{\circ} \mathrm{C}$ in the melatonin-implanted group and increased significantly $(P \leq 0.05)$ to $41.6 \pm 0.1{ }^{\circ} \mathrm{C}$ and $41.7 \pm 0.1{ }^{\circ} \mathrm{C} 4 \mathrm{~h}$ after LPS administration, respectively (Fig. 2). Additionally, in all ewes LPS administration induced rapid breathing and shortness of breath, sneezing, and stopped feed intake, anhedonia and reduced social interactions which are collectively termed 'sickness behavior'.The plasma melatonin concentration in melatoninimplanted ewes increased significantly $(P<0.05)$ from $8.2 \pm 2.2 \mathrm{pg} / \mathrm{mL}$ (before implantation) to $84.6 \pm 15.0 \mathrm{pg} /$ $\mathrm{mL}$ (one mo after implantation) while in shamimplanted stayed on the level of $9.6 \pm 1.1 \mathrm{pg} / \mathrm{mL}$. As shown on Table 2 immunoreactive IL-1 $\beta$ was not detected in blood plasma collected $1 \mathrm{~h}$ before LPS in 2 out of 6 ewes in sham-implanted group and in 4 out of 7 ewes in melatonin-implanted group. In other ewes IL-1 $\beta$ concentration ranged from 49.4 to $197.2 \mathrm{pg} / \mathrm{mL}$ and 128.6 to $192.7 \mathrm{pg} / \mathrm{mL}$ in sham- and melatonin-implanted ewes, respectively. Two and a half $\mathrm{h}$ after LPS administration the concentration of IL- $1 \beta$ increased in all investigated animals and reached the mean level of $159.3 \pm 53.1 \mathrm{pg} / \mathrm{mL}$ and $197.8 \pm 42.8 \mathrm{pg} / \mathrm{mL}$ in shamand melatonin-implanted ewes, respectively. Melatonin did not affect IL-1 $\beta$ concentration in blood plasma. In CSF collected before LPS, IL-1 $\beta$ was not detected in 2 out of 7 ewes in melatonin group. In sham-implanted ewes IL-1 $\beta$ ranged from 13.5 to $51.7 \mathrm{pg} / \mathrm{mL}$ while in other melatonin-implanted ewes ranged from 11.8 to 67.4 pg/mL. After LPS treatment the mean concentration of IL-1 $\beta$ increased in all investigated animals in sham-implanted $(129.8 \pm 54.2 \mathrm{pg} / \mathrm{mL})$ and melatoninimplanted $(139.6 \pm 51.5 \mathrm{pg} / \mathrm{mL})$ ewes. There was no effect $(P>0.05)$ of melatonin on CSF IL-1 $\beta$ concentration as well as no differences $(P>0.05)$ between IL-1 $\beta$ in

Table 2 Individual measurements of $\mathrm{IL}-1 \beta$ concentration $(\mathrm{pg} / \mathrm{mL})$ in blood plasma and cerebrospinal fluid (CSF) in sham-implanted and melatonin implanted ewes before and $3 \mathrm{~h}$ after lipopolysaccharide (LPS, $400 \mathrm{ng} / \mathrm{kg}$ ) administration

\begin{tabular}{|c|c|c|c|c|c|c|c|c|c|}
\hline \multicolumn{5}{|c|}{ Sham-implanted } & \multicolumn{5}{|c|}{ Melatonin-implanted } \\
\hline \multirow[b]{2}{*}{ Ewe \# } & \multicolumn{2}{|c|}{ Plasma, pg/mL } & \multicolumn{2}{|c|}{$\mathrm{CSF}, \mathrm{pg} / \mathrm{mL}$} & \multirow[b]{2}{*}{ Ewe \# } & \multicolumn{2}{|c|}{ Plasma, pg/mL } & \multicolumn{2}{|c|}{$\mathrm{CSF}, \mathrm{pg} / \mathrm{mL}$} \\
\hline & Before & After LPS & Before & After LPS & & Before & After LPS & Before & After LPS \\
\hline 1 & 0.0 & 65.3 & 27.8 & 48.0 & 1 & 143.3 & 211.0 & 26.4 & 410.8 \\
\hline 2 & 0.0 & 105.9 & 13.5 & 35.5 & 2 & 128. & 134.7 & 67.4 & 146.5 \\
\hline 3 & 53.0 & 58.5 & 21.0 & 50.4 & 3 & 0.0 & 210.7 & 19,2 & 39.6 \\
\hline 4 & 76.1 & 113.0 & 20.3 & 365.6 & 4 & 0.0 & 298.4 & 0.0 & 198.5 \\
\hline 5 & 197.2 & 399.0 & 22.8 & 66.7 & 5 & 0.0 & 80.3 & 0.0 & 12.3 \\
\hline \multirow[t]{2}{*}{6} & 49.4 & 214.2 & 51.7 & 213.7 & 6 & 192.7 & 378.7 & 24.2 & 54.0 \\
\hline & & & & & 7 & 0.0 & 71.0 & 11,8 & 115.4 \\
\hline $\begin{array}{l}\text { Mean } \\
( \pm \text { SEM })\end{array}$ & $\begin{array}{l}62.0 \\
( \pm 29.7)\end{array}$ & $\begin{array}{l}159.3^{\mathrm{a}} \\
( \pm 53.1)\end{array}$ & $\begin{array}{l}26.2 \\
( \pm 5.4)\end{array}$ & $\begin{array}{l}129.8^{a} \\
( \pm 54.2)\end{array}$ & & $\begin{array}{l}66.4 \\
( \pm 32.1)\end{array}$ & $\begin{array}{l}197.8^{\mathrm{a}} \\
( \pm 42.8)\end{array}$ & $\begin{array}{l}21.3 \\
( \pm 8.7)\end{array}$ & $\begin{array}{l}139.6^{\mathrm{a}} \\
( \pm 51.5)\end{array}$ \\
\hline
\end{tabular}

${ }^{\mathrm{a}}$ significant vs. concentration before LPS administration at $P<0.05$ 


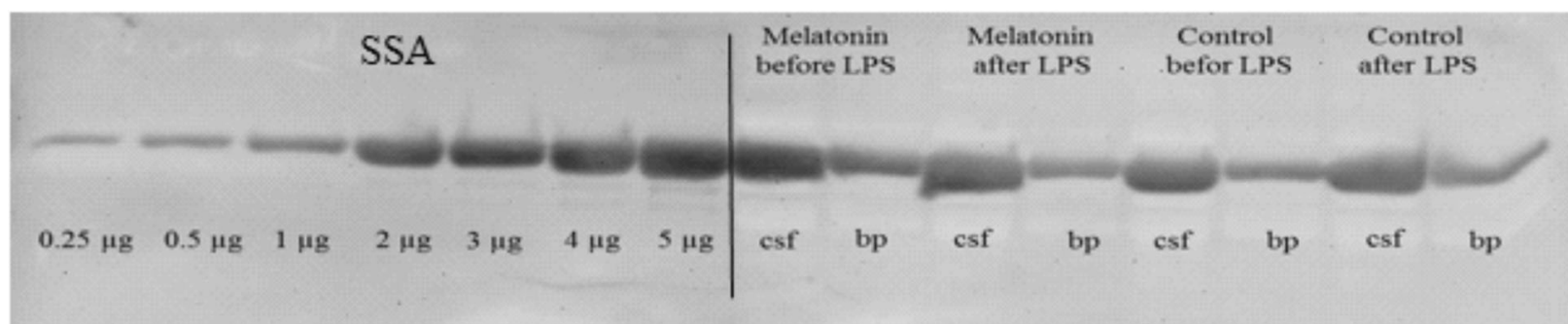

Fig. 3 Determination of albumin levels by western blot analysis in sheep cerebrospinal fluid (csf) and blood plasma samples (bp) collected before and $6 \mathrm{~h}$ after LPS administration. The densities of the bands were based on sheep serum albumin (SSA) dilution curve

blood plasma and CSF after LPS administration in both groups. No correlations was found between plasma and CSF IL-1 $\beta$ concentration after LPS administration in both sham- and melatonin-implanted groups $\left(\mathrm{r}^{2}=0.08\right.$; $P<0.29$ vs. $\left.\mathrm{r}^{2}=0.01 ; P<0.4\right)$.

The albumin concentrations in the CSF collected from the third brain ventricle and blood plasma were calculated on the base of linear dilution curve of sheep serum albumin detected by western blot method (Fig. 3) and then the integrity of BCSFB was estimated by ratio of albumin concentrations in the CSF and blood plasma (QAlb). Six hours after LPS administration mean QAlb was on the level of $0.20 \% \pm 0.05$ and $0.14 \% \pm 0.02$ $(P>0.05)$ in sham- and melatonin-implanted ewes and was similar to that observed before LPS administration $(0.18 \% \pm 0.02$ vs. $0.12 \% \pm 0.03, P=0.0572$, Fig. 4$)$. mRNA expression of $I l 1 B$ and its receptors Illr1 and Il1r2 in the CP collected $6 \mathrm{~h}$ after LPS administration were similar $(P>0.05)$ in both sham- and melatoninimplanted group (Fig. 5). Within 35 amplification cycles mRNA expression of $M m p 3$ and $M m p 9$ was not detected.

\section{Discussion}

Our results show that in ovariectomized and E2 treated ewes LPS in a dose of $400 \mathrm{ng} / \mathrm{mL}$ increased IL-1 $\beta$ concentration in blood plasma and the CSF early ( $2.5 \mathrm{~h}$ )

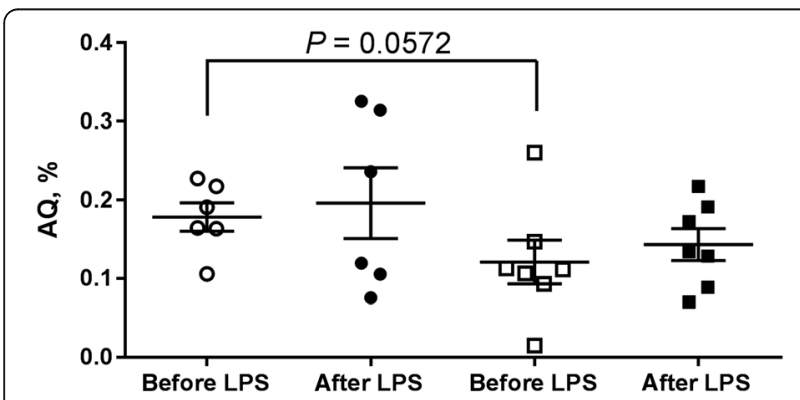

Fig. 4 Mean $( \pm$ SEM) cerebrospinal fluid albumin quotient (QAlb) before and after lipopolysaccharide (LPS, $400 \mathrm{ng} / \mathrm{kg}$ ) administration in sham- (circles) and melatonin-implanted (squares) adult ewes after LPS administration. In our previous study LH secretion as well as the GnRH release was observed to be suppressed $3 \mathrm{~h}$ after intravenous LPS administration in ewes [23]. The peripheral administration of LPS increases pro-inflammatory cytokine level IL-1 $\beta$, TNF $\alpha$ and IL-6 in blood plasma in many animals, however, there are species differences in a dose of LPS necessary to trigger the response [24-26]. Ewes are much more sensitive to LPS in comparison to mice and rats in which the range of the applied LPS doses is from $5 \mu \mathrm{g} / \mathrm{kg}$ to $5 \mathrm{mg} / \mathrm{kg}$. In our study the mean concentration of IL-1 $\beta$ reach the level of $159.3 \pm 53.1 \mathrm{pg} / \mathrm{mL}$ in plasma and $129.8 \pm 54.2 \mathrm{pg} / \mathrm{mL}$ in CSF in control and $197.8 \pm 42.8 \mathrm{pg} / \mathrm{mL}$ in plasma and $139.6 \pm 51.5 \mathrm{pg} / \mathrm{mL}$ in CSF of melatonin-implanted ewes. Individual plasma IL-1 $\beta$ levels were differentiated in both groups but means were similar to these observed in pigs $3 \mathrm{~h}$ after continuous LPS infusion in a dose of $250 \mathrm{ng} / \mathrm{kg} / \mathrm{h}$ [26]. We did not find any significant differences in IL- $1 \beta$ mean concentration between groups (sham- and melatonin-implanted) as well as between compartments (blood plasma and the CSF). This indicates the lack of melatonin slow-release implants effect on IL- $1 \beta$ concentration in both plasma and CSF early $(2.5 \mathrm{~h})$ after LPS administration. In our study, daytime plasma melatonin concentration in melatonin-implanted ewes were similar to this observed in our previous study [27] and reported by Skinner and Malpaux [28] for plasma collected at night. We did not observed any correlation between plasma and CSF concentration of IL- $1 \beta$ in both groups, what may suggests that transport of IL- $1 \beta$ from blood to the CSF is not only the source of IL- $1 \beta$ in the CSF early after LPS administration, and that CSF IL- $1 \beta$ originates from other sources. These findings are in line with results described by Qann and colleagues [29], who observed that in rats subseptic doses of LPS $(0.01-10 \mu \mathrm{g} /$ $\mathrm{kg}$ ) that are in range of the dose used in ewes induced $I l 1 B$ mRNA expression only in the CP, the circumventricular organs and meninges. Moreover, secretion of cytokines to the brain by activated cells of the BBB has been described as an additional, to saturable transport system, pathway of cytokine access to the brain [10]. 

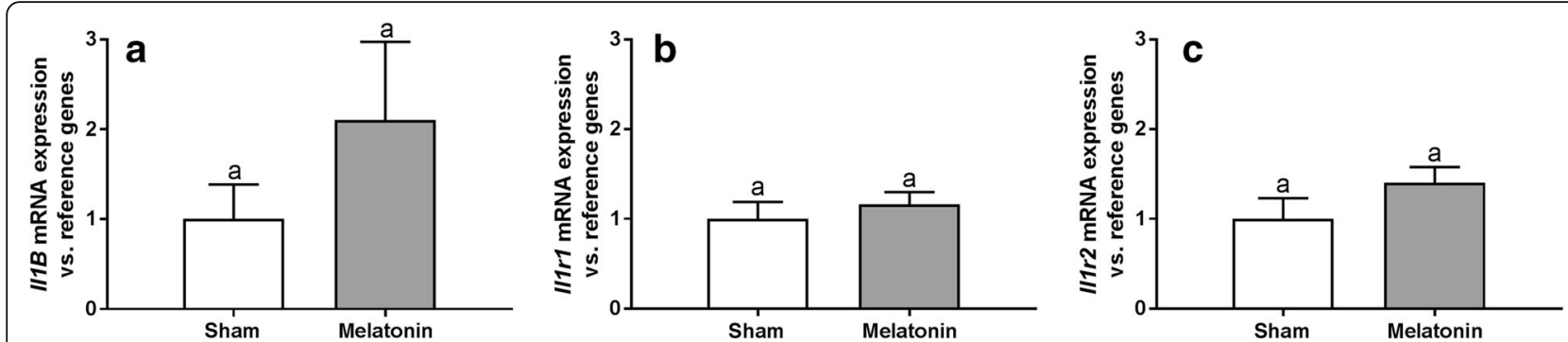

Fig. 5 The effect of sham- (white) and melatonin-implantation (grey) on the mean ( \pm SEM) relative relative gene expression for interleukin $1 \beta$ $(I / 1 B$; $\mathbf{a})$ and its receptor type I $(\| 1 r 1 ; \mathbf{b})$ and type II $(/ 11 r 2 ; \mathbf{c})$ in the choroid plexus of lipopolysaccharide (LPS)-treated adult ewes. Data presented on each panel were normalized to the average relative quantity of target gene expression in sham- and melatonin-implanted, which was set to 1.0

In addition to evaluating the effect of LPS alone and with melatonin from slow-release implants on the concentration of IL-1 $\beta$ in blood plasma and the CSF, the second aim of this study was to investigate the BBB permeability in ewes early after LPS administration. The integrity of brain barriers was estimated by the ratio of albumin concentrations in CSF and blood plasma. The QAlb, calculated in our study before LPS administration was similar to that obtained by Chen et al. [30] for young (1-2 yr) and middle aged (3-5 yr) ewes. Moreover, the QAlb on the level of $0.18 \% \pm 0.02$ in shamimplanted and $0.12 \% \pm 0.03$ in melatonin-implanted ewes observed in ewes before LPS administration, despite the difference at the very edge of significance $(P=0.0572)$, seem to confirm previous observation related with melatonin as possible modulator of molecule passage throughout the brain barriers in sheep. These include: 1) higher steroids access to the CSF during long than short days in female sheep [18, 31], 2) higher passage of leptin from the periphery to the CSF in rams during long days than short days [32], 3) higher expression of tight junction proteins in the $\mathrm{CP}$ in ewes during short than long days [33] and 4) photoperiod-dependent change in CSF proteome composition in ewes [34]. The lack of differences in QAlb before and after LPS administration, found in our studies, indicates that despite the high level of IL-1 $\beta$ in blood and the CSF the integrity of $\mathrm{BBB}$ and BCSFB was not damaged $6 \mathrm{~h}$ after LPS administration. Indeed, in the CP collected $6 \mathrm{~h}$ after LPS administration the expression of mRNA for $M m p 3$ and 9, that are responsible for degradation of extracellular matrix and therefore for increase of BCSFB permeability was very weak.

\section{Conclusions}

In summary we demonstrated that intravenous LPS administration in ewes induces rapid increase of IL$1 \beta$ in blood plasma and the CSF that is not modulated by melatonin from slow-release implants. The lack of changes in the brain barrier permeability early after LPS administration, at the time when LPSdependent suppression of GnRH secretion was observed in ewe, indicates that LPS acts mainly at the $\mathrm{BBB}$ and BCSFB which are a place for elaboration of signal molecules that communicate peripheral immune status to the brain.

\section{Abbreviations}

Actb: $\beta$-actin; BBB: Blood-brain barrier; BCSFB: Brain-cerebrospinal fluid barrier; bp: Blood plasma; CP: Choroid plexus; CSF: Cerebrospinal fluid; E2: Oestradiol; Gapdh: Glycer-aldehyde-3-phosphate dehydro-genase; GnRH: Gonadotropin releasing hormone; Hdac1: Histone deacetylase 1; LL: Interleukin; IL1R1: Interleukin 1 receptor type I; IL-1R2: Interleukin 1 receptor type I; LH: Luteinizing hormone; LPS: Lipopolysaccharide; Mmp: Matrix metalloproteinase; MT: Melatonin receptor; QAlb: Albumin quotient; RIA: Radioimmunoassay; SDS: Sodium dodecyl sulfate; SEM: Standard error of the mean; SSA: Sheep serum albumin; TBST: Tris buffer saline with Tween; TNF: Tumor necrosis factor

\section{Acknowledgements}

We would like to thank Dr. Przemysław Gilun and Joanna Winnicka for expert technical assistance.

Marta Kowalewska participated as a part of $\mathrm{PhD}$ thesis.

\section{Funding}

This work was supported by a project funded by the National Science Centre allocated on the basis of decision-DEC 2011/03/B/NZ9/00118. Participation of Dr. T. Misztal, Dr. M. Jalynski and Dr. K. Zabek was supported by Ministry of Science and High Education.

\section{Availability of data and materials}

All data supporting our findings are included in the manuscript.

\section{Authors' contributions}

SJ, HAP and JM conceived and designed the experiment; SJ, KM, SA, MT, JM, HAP and ZK performed animal experiment; KM, SA, MA and ZK performed laboratory analysis; SJ, KM and MA analyzed data; SJ, MK and MT prepared the manuscript. All authors read and approved the final manuscript.

Ethics approval and concent to participate

Experimental protocol was approved by the Local Ethics Committee (No. 25/2012).

Consent for publication

All authors read and approved the final manuscript for publication.

Competing interests

The authors declare that they have no competing interests.

\section{Author details}

${ }^{1}$ Institute of Animal Reproduction and Food Research, Polish Academy of Sciences, Olsztyn, Poland. ${ }^{2}$ The Kielanowski Institute of Animal Physiology and Nutrition, Polish Academy of Sciences, Jablonna n/Warsaw, Olsztyn, 
Poland. ${ }^{3}$ Veterinary Medicine Faculty, University of Warmia and Mazury, Olsztyn, Poland. ${ }^{4}$ Department of Sheep and Goat Breeding, Animal Bioengineering Faculty, University of Warmia and Mazury in Olsztyn, Olsztyn, Poland.

Received: 23 March 2017 Accepted: 21 August 2017

Published online: 01 October 2017

\section{References}

1. Tomaszewska-Zaremba D, Herman A. The role of immunological system in the regulation of gonadoliberin and gonadotropin secretion. Reprod Biol. 2009:9:11-23.

2. Tremellen $\mathrm{K}$, Pearce $\mathrm{K}$, editors. Nutrition, fertility, and human reproductive function. Boca Raton: CRC Press; 2015.

3. Watanobe $H$, HayakawaY. Hypothalamic interleukin-1 $\beta$ and tumor necrosis factor-a, but not interleukin-6, mediate the endotoxin-induced suppression of the reproductive axis in rats. Endocrinology. 2003;144:4868-75.

4. Herman AP, Misztal T, Herman A, Tomaszewska-Zaremba D. Expression of interleukin (IL)-1b and $\mathrm{IL}-1$ receptors genes in the hypothalamus of anoestrous ewes after lipopolysaccharide treatment. Reprod Domest Anim. 2010;45:e426-33.

5. Skipor J, Thiery JC. The choroid plexus-cerebrospinal fluid system: under valuated pathway of neuroendocrine signaling into the brain. Acta Neurobiol Exp. 2008;68:414-28.

6. Vitkovic L, Konsman JP, Bockaert J, Dantzer R, Homburger V, Jacque C. Cytokine signals propagate through the brain. Mol Psychiatry. 2000:5:604-15.

7. Blamire AM, Anthony DC, Rajagopalan B, Sibson NR, Perry VH, Styles P. Interleukin-1 beta -induced changes in blood-brain barrier permeability, apparent diffusion coefficient, and cerebral blood volume in the rat brain: a magnetic resonance study. J Neurosci. 2000;20:8153-9.

8. Strazielle N, Khuth ST, Murat A, Chalon A, Giraudon P, Belin MF, et al. Proinflammatory cytokines modulate matrix metalloproteinase secretion and organic anion transport at the blood-cerebrospinal fluid barrier. J Neuropathol Exp Neurol. 2003;62:1254-64

9. Alluri H, Wilson RL, Shaji CA, Wiggins-Dohlvik K, Patel S, Liu Y, et al. Melatonin preserves blood-brain barrier integrity and permeability via matrix metalloproteinase-9 inhibition. PLoS One. 2016; https://doi.org/10 1371/journal.pone.0154427.

10. Banks WA, Erickson MA. The blood-brain barrier and immune function and dysfunction. Neurobiol Dis. 2010;37:26-32.

11. Skinner RA, Gibson RM, Rothwell HJ, Pinteaux E, Penny Jl. Transport of interleukin-1 across cerebromicrovascular endothelial cells. Br J Pharmacol. 2009:156:1115-23.

12. Colotta F, Re F, Muzio M, Bertini R, Polentarutti N, Sironi M, et al. Interleukin1 type II receptor: a decoy target for IL-1 that is regulated by IL-4. Science. 1993:261:472-5.

13. Sims JE, Gayle MA, Slack JL, Alderson MR, Bird TA, Giri JG, et al. Interleukin 1 signaling occurs exclusively via the type I receptor. Proc Natl Acad Sci U S A. 1993:90:6155-9.

14. Daneman R, Zhou L, Agalliu D, Cahoy JD, Kaushal A, Barres BA. The mouse blood-brain barrier transcriptome: a new resource for understanding the development and function of brain endothelial cells. PLoS One 2010;5: e13741.

15. Liddelow SA, Temple S, Møllgård K, Gehwolf R, Wagner A, Bauer $\mathrm{H}$, et al Molecular characterisation of transport mechanisms at the developing mouse blood-CSF interface: a transcriptome approach. PLoS One. 2012;7:1-18.

16. Cogé SP, Guenin I, Fery I, Migaud M, Devavry S, Slugocki C, et al. The end of a myth: cloning and characterization of the ovine melatonin MT(2) receptor. $\mathrm{Br}$ J Pharmacol. 2009;158:1248-62.

17. Chemineau P, Malpaux B, Delgadillo JA, Guerin Y, Ravault JP, Thimonier J, et al. Control of sheep and goat reproduction: use of light and melatonin. Anim Reprod Sci. 1992;30:157-84.

18. Thiéry JC, Lomet D, Schumacher M, Liere P, Tricoire H, Locatelli A, et al. Concentrations of estradiol in ewe cerebrospinal fluid are modulated by photoperiod through pineal-dependent mechanisms. J Pineal Res. 2006;41: 306-12.

19. Skipor J, Misztal T, Kaczmarek MM. Independent changes of thyroid hormones in blood plasma and cerebrospinal fluid after melatonin treatment in ewes. Theriogenology. 2010;74:236-45.
20. Herman AP, Herman A, Haziak K, Tomaszewska-Zaremba D. Immune stress up regulates TLR4 and Tollip gene expression in the hypothalamus of ewes. J Anim Feed Sci. 2013;22:13-8.

21. Misztal T, Romanowicz K, Barcikowski B. Seasonal changes of melatonin secretion in relation to the reproductive cycle in sheep. J Anim Feed Sci. 1996:5:35-48.

22. Zhao S, Fernald RD. Comprehensive algorithm for quantitative real-time polymerase chain reaction. J Comput Biol. 2005;12:1047-64.

23. Herman AP, Krawczyńska A, Bochenek J, Haziak K, Romanowicz K, Misztal T, et al. The effect of rivastigmine on the LPS-induced suppression of $\mathrm{GnRH}$ / $\mathrm{LH}$ secretion during the follicular phase of the estrous cycle in ewes. Anim Reprod Sci. 2013;138:203-12.

24. Creasey AA, Stevens P, Kenney J, Allison AC, Warren K, Catlett R, et al. Endotoxin and cytokine profile in plasma of baboons challenged with lethal and sublethal Escherichia Coli. Circ Shock. 1991:33:84-91.

25. Givalois L, Dornand J, Mekaouche M, Solier MD, Bristow AF, Ixart G, et al. Temporal cascade of plasma level surges in $\mathrm{ACTH}$, corticosterone, and cytokines in endotoxin-challenged rats. Am J Phys. 1994;267:R164-R70.

26. Aberg AM, Abrahamsson P, Johansson G, Haney M, Winsö O, Larsson JE. Does carbon monoxide treatment alter cytokine levels after endotoxin infusion in pigs? A randomized controlled study J Inflamm. 2008;5:13.

27. Kowalewska M, Szczepkowska A, Herman AP, Pellicer-Rubio MT, Jalynski M, Skipor J. Melatonin from slow-release implants did not influence the gene expression of the lipopolysaccharide receptor complex in the choroid plexus of seasonally anoestrous adult ewes subjected or not to a systemic inflammatory stimulus. Small Rumi Res. 2017:147:1-7.

28. Skinner DC, Malpaux B. High melatonin concentrations in third ventricular cerebrospinal fluid are not due to Galen vein blood recirculating through the choroid plexus. Endocrinology. 1999;140:4399-405.

29. Quan N, Stern EL, Whiteside M, Herkenham M. Induction of proinflammatory cytokine mRNAs in the brain after peripheral injection of subseptic doses of lipopolysaccharide in the rat. J Neuroimmunol. 1999;93: 72-80.

30. Chen RI, Chen CPC, Preston JE. Elevation of CSF albumin in old sheep: relations to CSF turnover and albumin extraction at blood-CSF barrier. Neurochem. 2010;113:1230-9.

31. Thiéry JC, Robel P, Canepa S, Delaleu B, Gayrard V, Picard-Hagen N, et al. Passage of progesterone into the brain changes with photoperiod in the ewe. Eur J Neurosci. 2003;18:895-901.

32. Adam CL, Findlay PA, Miller DW. Blood-brain leptin transport and appetite and reproductive neuroendocrine responses to intracerebroventricular leptin injection in sheep: influence of photoperiod. Endocrinology. 2006;147: 4589-98.

33. Lagaraine C, Skipor J, Szczepkowska A, Dufourny L, Thiéry JC. Tight junction proteins vary in the choroid plexus of ewes according to photoperiod. Brain Res. 2011;1393:44-51.

34. Teixeira-Gomes AP, Harichaux G, Gennetay D, Skipor J, Thiery JC, Labas V. Al. Photoperiod affects the cerebrospinal fluid proteome: a comparison between short day- and long day-treated ewes. Domest Anim Endocrinol. 2015;53:1-8.

35. Herman AP, Krawczyńska A, Bochenek J, Antushevich H, Herman A, Tomaszewska-Zaremba D. Peripheral injection of SB203580 inhibits the inflammatory-dependent synthesis of proinflammatory cytokines in the hypothalamus. BioMed Res Int. 2014; doi: https://doi.org/10. 1155/2014/475152.

36. Herman AP, Bochenek J, Król K, Krawczyńska A, Antushevich H, Pawlina B, et al. Central interleukin-1 $\beta$ suppresses the nocturnal secretion of melatonin Mediat Inflamm. 2016. https://doi.org/10.1155/2016/2589483. 